\title{
Short-Term Conservation of Somatic Embryo Clusters for Date Palm (Phoenix Dactylifera 1.) Cv. Amry
}

\author{
Abdrabboh', G.A.; Khalifa', S.M; Elsharabasy², S.F. and G. E. Abd-kariem² \\ ${ }^{1,2}$ Department of Horticulture, Faculty of Agriculture, Al-Azhar University, ,Cairo, Egypt. \\ ${ }^{3,4}$ The Central Lab of date palm Researches and Development, Agriculture Research Center, Giza, Egypt. \\ Corresponding author: gabdrabboh65@yahoo.com
}

\begin{abstract}
This work aimed to develop a conservation protocol for date palm cv. Amry, an Egyptian semi dry rare cultivar. Slow growth conditions of storage studied by using low temperature at $15^{\circ} \mathrm{C}$, beside the manipulation of salt strength of nutrient medium,( MS, 1/2 MS or1/4 MS) in combination with osmotic agent addition sucrose, sorbitol, or mannitol at constant concentration $(0.3 \mathrm{M})$ for each, to conserve somatic embryos clusters explants, which obtained previously through direct somatic embryogenesis of inflorescences explants. Survival percentage and recovery were evaluated after 6 months of conservation period. Results showed that conserved somatic embryos clusters explants on full MS, $1 / 2$ MS, conservation medium supplemented with sucrose or sorbitol recorded the highest significant survival percentage on full MS, $1 / 2 \mathrm{MS}$, where the lowest significant survival percentage was obtained when somatic embryos were conserved on 1/4 medium supplemented with mannitol . Best shoot number and shoot length recovery under normal growth conditions achieved on conservation medium supplemented with sucrose in comp inaction with reducing the full MS salt strength to the half for 6 months of conservation period under low temperature at $15^{\circ} \mathrm{C}$.
\end{abstract}

Keywords: Date palm, Sorbitol, Mannitol, Sucrose, Slow growth conditions, Germplasm conservation.

\section{Introduction}

Date palm tree (Phoenix dactylifera L.) is an important commercial crop for Arab countries, in Asia and Africa, also, there are other countries where dates trees can be found like in Southern Africa, South America, Mexico, the United States (Arizona, Texas and southern California) and Australia. This oldest tree is Angiosperms, monocotyledon belongs to Arecaceae family, Phoenix genera (Gantait et al., 2018). Date palm in Egypt lies as the top of the largest twenty dates producer countries in the world, where Egyptian dates production represented $17.7 \%$ of world production (FAO, 2018). In recent years the in vitro techniques have a great of interest concerning the date palm micropropagation and germplasm conservation, over the common methods (Al-Khayri and Naik, 2017). Date palm genetic materials as germplasm are worthy, because it implicates a distinction of genotypes, that required to be preserved and developed for many endangered, elite, and economical varieties (El-Dawayati, 2017). Progress in biotechnological studies gave new opportunities for in vitro conservation of cultures, which gained varying degrees of success, for many species and protocols systems through, cryopreservation or slow growth conditions application, depending on the storage duration required. (Negri et al., 2000; Engelmann, 2011; Sabah et al., 2013). Slow-growth techniques for short and mid-term storage are based primarily on conditions that allow minimal growth cells, tissues, or organs by reducing temperature or adding osmotic regulators and growth retardants to the medium, these slow-growth techniques are widely used due to their reliability (EI-Bahr et al., 2016). The principle of slow growth storage allows a safe use of in vitro culture without the disadvantages of frequent sub cultivation as genotypes can be effectively conserved without the loss of viability in the form of disease-free stocks in a controlled environment (Thakur et al., 2015 ). Explants of in vitro date palm for germplasm conservation have many kinds i.e. callus cultures, meristem tips, somatic embryos, shoot tips, and multiple shoot cultures (Gantait et al., 2018). Temperature is the most important factor to slow down both, metabolic process and biological activities of conserved plant materials (Bekheet, 2017) Callus, and shoot tip cultures of Egyptian cultivars of date palm were successfully preserved for short term storage at $15^{\circ} \mathrm{C}$ (El-Dawayati et al., 2013.; El-Dawayati, 2017). Reducing the growth and increasing the storage life by the addition of osmotic agents i.e. sucrose, sorbitol, ribose and mannitol to medium that the culture have been proved to be efficient (Muñoz1 et al., 2019). Also, modulation in conservation medium under slow growth condition were successfully achieved with palm trees and other plants (Lopez-Puc 2013, Chauhan et al., 2019). The aim of our work is to study the in vitro germplasm conservation of date palm for the rare cultivar Amry, by using somatic embryos clusters explants resulted from direct somatic embryogenesis protocol of date palm inflorescences. Modification of the strength of basal salts of nutrient media, with different type of osmotic agent (sucrose, sorbitol, and mannitol) were evaluate after short term storage for six months at low temperature $\left(15^{\circ} \mathrm{C}\right)$, on the survival and recovery after in vitro preservation under slow growth conditions. 


\section{Materials and Methods}

Somatic embryos clusters (8-10 somatic embryo/ explant) of Amry cv date palm inflorescences were cultured on different strength of Murashjge and Skoog (1962) (MS ) nutrient salt i.e. ( Full MS, 1/2 MS and 1/4 MS) supplemented with different sugar types i.e. (sucrose, sorbitol or mannitol at $0.3 \mathrm{M}$ for each medium as recommended by (Eldawayati, 2008 ). A conservation medium component for all studied treatments was supplemented with $0.05 \mathrm{mg} / 1$ (BA), $0.1 \mathrm{mg} / \mathrm{l} \mathrm{NAA}, 1.0 \mathrm{~g} / \mathrm{l}$ activated charcoal (AC) and $8.0 \mathrm{~g} / \mathrm{L}$ agar. The culture jars of each conservation treatment were conserved under complete darkness at $15^{\circ} \mathrm{C}$ for 6 months.

\section{Recovery medium:-}

After 6 months of conservation period, the conserved somatic embryos clusters were transferred to fresh recovery medium consists j.e. MS nutrient medium supplemented with $0.05 \mathrm{mg} / \mathrm{L} \mathrm{BA}, 0.1 \mathrm{mg} / \mathrm{L}$ NAA, $100 \mathrm{mg} / \mathrm{L}$ myo- inositol, $170 \mathrm{mg} / \mathrm{L}$ $\mathrm{KH}_{2} \mathrm{PO}_{4} 2 \mathrm{H}_{2} \mathrm{O}, 30 \mathrm{~g} / \mathrm{L}$ sugar and $4 \mathrm{mg} / \mathrm{L}$ thiamine $\mathrm{HCl}$. All cultures were incubated at $27 \pm 1^{\circ} \mathrm{C}$ under 16:8-h light/dark. All media were solidified with $6 \mathrm{~g} / \mathrm{L}$ agar, for further somatic embryos germination and shoots developing under normal growth conditions of incubation ، at $27 \pm 1^{\circ} \mathrm{C}$ under 16:8-h light/dark. In all conservation treatments and recovery media, $\mathrm{pH}$ was adjusted to $5.7 \pm 0.1$ prior to addition of agar. The medium of each treatment was distributed into culture jars $(150 \mathrm{~mL})$ where each one contained $40 \mathrm{ml} / \mathrm{L}$. The culture jars were immediately capped with polypropylene closure and then the medium was sterilized by autoclaving at $121^{\circ} \mathrm{C}$ and $15 \mathrm{Ibs} / \mathrm{in}^{2}$ for $20 \mathrm{~min}$. Each conservation treatment contained 3 replicates and each replicate represented by 3 culture jars and each jar contained one cluster of somatic embryos explant.

\section{Data were calculated after 3 subcultures of normal growth conditions after 6 months of conservation period as follows.}

Survival percentage of conserved explants after each conservation period of different treatments was determined after returning the conserved explants on recovery medium under normal growth conditions for 4 weeks. After each conservation period regrowth capacity of conserved explants were taken after three subcultures with (six weeks) intervals on recovery medium under normal growth conditions. The browning degree/ explant, secondary embryos formation degree/explant, the new shoot number / explant and new shoot length/ explant proliferated from conserved somatic embryos clusters. The data representing expressed as scores visually. Browning degree and secondary embryos formation data were scored visually. (follow as, $0=$ no change; $1=$ below average; $2=$ average; $3=$ above average; $4=$ high $; 5$
= very high), following the recommendation of ElDawayati et al. (2018). Statistical analysis.

The randomized factorial design was used and data were subjected to analysis of variance. Separation of means among treatments was determined using L.S.D test at 5\% according to Schroder (1970).

\section{III- Results and Discussion:-}

The prepared somatic embryos clusters explants of date palm cv.Amry, conserved for 6months, by studying the effect of minimal growth conditions of stroge using MS nutrient basal salts at different strengths as conservation media ( $1 \mathrm{MS}, 1 / 2$ MS or1/4 MS), with the addition of different osmotic agents i.e. sucrose, sorbitol, or mannitol at of the same concentration $(0.3 \mathrm{M})$ for each. present data showed the results of survival and recovery potential after the tested minimal growth conditions of storage.

\section{III-I- Survival percentage:-}

Data in Table (1) showed that all conserved somatic embryos clusters which cultured on MS conservation medium supplemented with sucrose treatments for 6 months at $15^{\circ} \mathrm{C}$ under minimal growth conditions, possessed $100 \%$ of survival percentage, when they returned to recover medium on normal growth conditions for 4 weeks after conservation period. On the other hand, somatic embryo clusters cultured on MS conservation medium supplemented with sorbitol treatments ranked significantly at the second order of survival percentage since they gained $(97.77 \%)$ during recovery on normal growth conditions after 4 weeks of conservation period, while the lowest results were recorded for somatic embryos that conserved on MS supplemented with mannitol as they gained 94.44 survival percentage. Also, the addition of osmotic to culture has been proved to be efficient in reducing growth and increasing the storage life of many in vitro grown tissues of different plant species (George et al., 2008). In vitro, slow-growth storage was efficiently used for mid-term conservation of elite clones of (Chlorophytum borivilianum Sant. et Fernand) when sucrose concentrations at $120 \mathrm{~g} / \mathrm{L}$ were added, which enabled $100 \%$ survival from cultures stored for 4 months without any subculture or medium addition (Chauhan et al., 2016). Staikidou et al., (2005) mentioned that it is difficult in separating substrate and osmotic effects of sucrose. Sugar alcohols are not usually metabolized by plant tissues and generally cannot be used as carbon sources. For this reason mannitol and sorbitol are frequently employed as osmotic to modify the water potential of a culture medium. In these circumstances sufficient sucrose must also be present to supply the energy require to the tissue. Also, (Pan et al., 2014) reported that to reduce the plant 
metabolism, the environment conditions i.e. temperature, photoperiod, light intensity, etc. or culture media composition i.e. (organic and inorganic nutrients, osmotic regulators, or growth inhibitors) can be modified along the incubation period. It is noticed clearly, from data in Table (1) that MS conservation medium at strength gave the highest significant results of survival percentage for conserved somatic embryos explants after 6 months of conservation period, when returning to normal growth conditions for 4 weeks. Reducing the strength of (MS) nutrient salts of conservation medium to half or quarter strength resulted significantly in reducing the survival percentage for conserved somatic embryos explants when returning to normal growth conditions, after 6 months of conservation period since the gained
(97.77, 94.44 respectively).On contrast, Rahayu, et al., (2015) found that MS medium at half strength is recommended for storage C. pubescens for 16 weeks with no sub-culture. The interaction results of the effect of both sugar type and MS salt strengths of minimal growth conditions of our results revealed that, supplementation the medium with sorbitol at 0.3 M, compiled with 1/4 MS strength and addition of mannitol at $0.3 \mathrm{M}$ compiled with $1 / 2 \mathrm{MS}$ recorded the same value of the survival percentage (93.33), mannitol sugar type at $0.3 \mathrm{M}$ in compilation with the 1/4 MS recorded significantly the lowest value of the survival percentage of conserved somatic embryos explants after culturing on the normal growth conditions for 4 weeks, after 6 months of conservation period.

Table 1. Effect of sugar types and MS media strengths during conversion stage on survival percentage rate of date palm cv. Amry.

\begin{tabular}{|c|c|c|}
\hline Sugar Types (M) & MS strength(g) & survival percentage \\
\hline Sucrose $\quad(0.3 \mathrm{M})$ & $\begin{array}{ll}+ & \text { MS ( Full MS) } \\
+\quad 1 / 2 \mathrm{MS} \\
+\quad 1 / 4 \mathrm{MS} \\
+\end{array}$ & $\begin{array}{l}100 \\
100 \\
100\end{array}$ \\
\hline Mean A & & 100 \\
\hline Sorbitol & $\begin{array}{ll}+ & \mathrm{MS} \\
+\quad 112 \mathrm{MS} \\
+\quad 114 \mathrm{MS}\end{array}$ & $\begin{array}{l}100 \\
100 \\
93.33\end{array}$ \\
\hline Mean A & & 97.77 \\
\hline Mannitol $\quad(0.3 \mathrm{M})$ & $\begin{array}{ll}+ & \mathrm{MS} \\
+ & 112 \mathrm{MS} \\
& 114 \mathrm{MS} \\
+ & \\
\end{array}$ & $\begin{array}{l}100 \\
93.33 \\
90.00\end{array}$ \\
\hline Mean A & & 94.44 \\
\hline $\begin{array}{ll}\text { Mean B } & \\
\mathrm{MS} & =100 \\
1 \backslash 2 \mathrm{MS} & =97.7 \\
1 / 4 \mathrm{MS} & =94.4\end{array}$ & & \\
\hline $\begin{array}{ll}\text { LSD at } 0.05 \text { for } & \\
\text { Sugar type }(\mathrm{A}) & =1.89 \\
\text { MS strength }(\mathrm{B}) & =2.70( \\
\mathrm{AB} & =4.67 \\
\end{array}$ & & \\
\hline
\end{tabular}

\section{III-2-Browning rate:}

Browning appearance of regenerated conserved somatic embryos clusters under normal growth conditions for three subcultures after conservation periods for 6 months, of minimal growth conditions were significantly affected by sugar type added to conservation medium. Table 2 showed the conserved somatic embryos clusters on conservation medium with sucrose addition recorded the lowest significant results for browning appearance (2.81) during conversion stage. The highest significant result for browning appearance under normal growth conditions of the recovered somatic embryos clusters were recorded when conserved on MS conservation medium supplemented with mannitol sugar for 6 months. Our results are in agreement with those obtained by El-Dawayati et al., (2018) who reported that browning as physiological disorders were induced by increasing the concentration of preservation period .Also this was in agreement with Moges et al., (2003) in African violet, Shibli et al., (2005) in date palm and Baghdadi et al., (2011) in Wild Crocus. However, ElDawayati, (2008) reported that the highest significant browning degree value of conserved callus explants of 
date palm Gundila cv. at $15^{\circ} \mathrm{C}$ was obtained when callus explants conserved on conservation medium supplemented with mannitol sugar. From data in Table (2) there was no significant differences between the browning degree of regenerated conserved somatic embryos clusters regarding media strength for three subcultures, (MS, 1/2 MS and 1/4 MS) where they recorded $(3.52,3.15,3.00$ respectively). The obtained results showed that the lowest significant value of the browning appearance of regenerated conserved somatic embryos clusters during normal growth conditions for three subcultures, were exhibited by minimal growth conditions of half strength of MS salts supplemented with sucrose.

Table 2. Effect of sugar types and MS media strengths during conversion stage on browning rate of date palm cv. Amry .

\begin{tabular}{|c|c|c|}
\hline Sugar types & MS strength & Browning \\
\hline$(0.3 \mathrm{M})$ & $+\quad$ MS (Full MS) & 2.89 \\
\hline & $+112 \mathrm{MS}$ & 2.55 \\
\hline & $1 \backslash 4 \mathrm{MS}$ & 3.00 \\
\hline & + & \\
\hline Mean A & & 2.81 \\
\hline sorbitol & $+\mathrm{MS}$ & 3.11 \\
\hline & $+112 \mathrm{MS}$ & 3.00 \\
\hline & $1 \backslash 4 \mathrm{MS}$ & 3.55 \\
\hline & + & \\
\hline Mean A & & 3.22 \\
\hline mannitol & $+\mathrm{MS}$ & 3.00 \\
\hline & $+112 \mathrm{MS}$ & 3.78 \\
\hline & $\begin{array}{r}114 \mathrm{MS} \\
+\quad 1\end{array}$ & 4.11 \\
\hline Mean A & & 3.63 \\
\hline Mean B & & \\
\hline $\mathrm{MS}=3.52$ & & \\
\hline $1 / 2 \mathrm{MS}=3.15$ & & \\
\hline $1 / 4 \mathrm{MS}=3.0$ & & \\
\hline LSD at 0.05 for & & \\
\hline Sugar type $\quad(A)=0.31$ & & \\
\hline MS strength $(\mathrm{B}) \quad=\mathrm{NS}$ & & \\
\hline $\mathrm{AB}=0.9$ & & \\
\hline
\end{tabular}

\section{III-3- Secondary embryos formation:-}

Data presented in table (3) clearly showed that addition of sugar as osmotic has a significant effect on the formation of secondary embryos form the conserved explants on the recovery medium after conservation period. Sucrose inclusion in conservation medium for somatic embryos clusters of date palm gave the highest regeneration value of secondary embryos formation after 6months of conservation period (2.92), These results are in harmong with those resulted by Hassan et al., (2016) who reported that sucrose at $0.3 \mathrm{M}$ to the conservation medium showed the highest significant value of recovery percentage of conserved somatic embryo clusters of sewy date palm cultivar after conservation period up to 10 months. Our results also indicated that, addition of mannitol sugar addition to conservation medium for somatic embryos clusters of date palm gave the lowest regeneration value of secondary embryos formation after 6months of conservation,
Obviously, the strength of (MS) nutrient salts of conservation medium of somatic embryos clusters failed to induce significant fact on regeneration of secondary embryos formation after 6months of conservation period. Also, there is no interaction effect for the combination of sugar type and the salt strength of (MS) medium on the secondary embryos formation during the recovery stage of somatic embryos clusters under normal growth conditions. 
Table 3. Effect of sugar types and MS media strengths during conversion stage on Secondary rate of date palm cv. Amry.

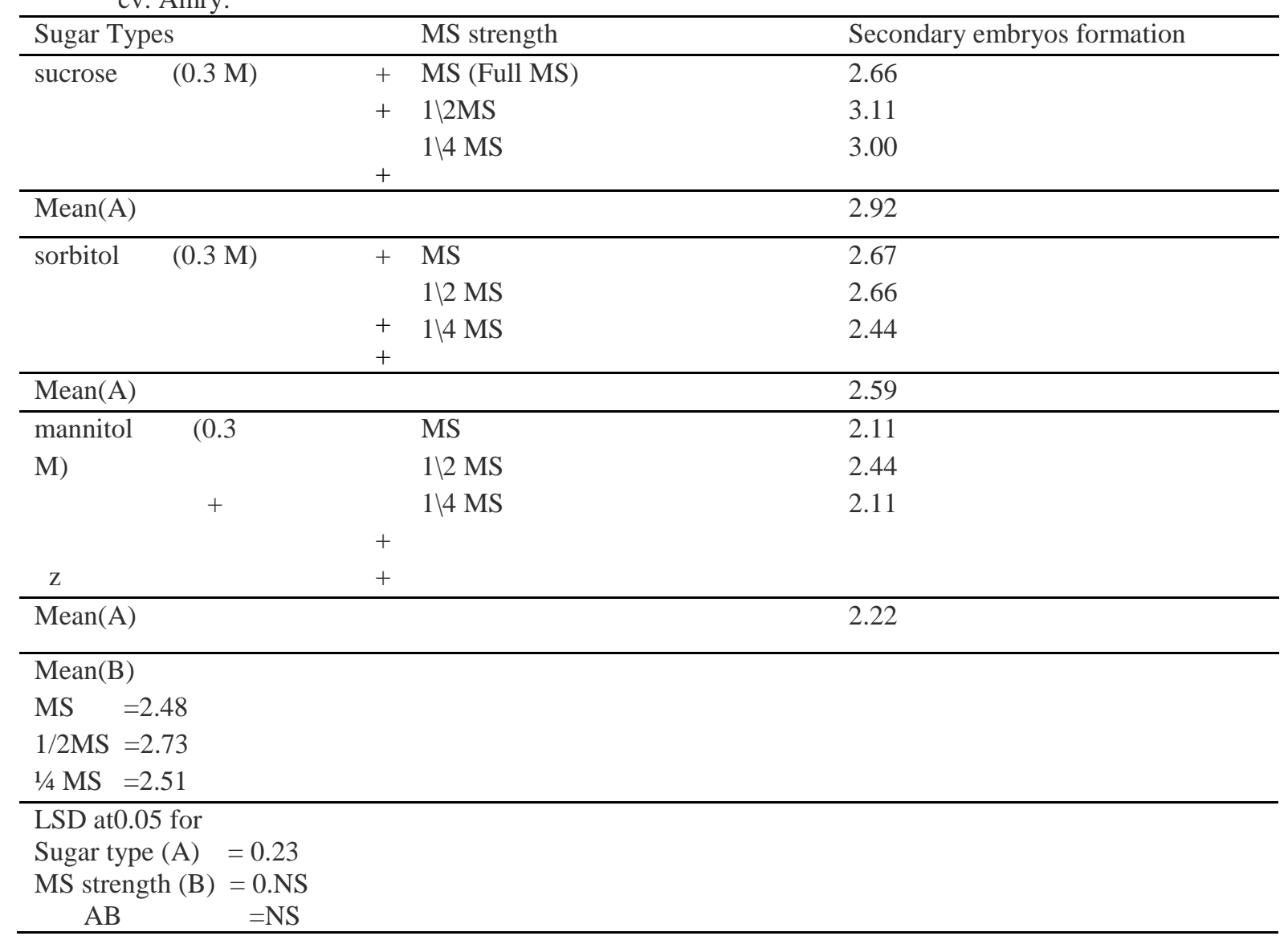

\section{III-4-Shoot number /explant:-}

Data in Fig (1) showed the somatic embryos clusters which conserved on MS medium supplemented with Sucrose under minimal growth conditions. It is appear that the highest significant number of shoots explant when transferred to for three subcultures since it gained (21.82)in comparison with other treatments. The illustrated data explained that the number of regenerated shoots which proliferated from conserved somatic embryos clusters of date palm Amry cv. were affected significantly with different types of sugar and MS strengths. Best shoot number recovery from conserved explants was achieved when somatic embryo clusters conserved for 6 months on conservation medium supplemented with sucrose sugar type at $0.3 \mathrm{M}$ compiled with the half strength MS medium. These results are in harmony with those of El-Dawayati et al., (2018) who found that the best results of shoot number / explant of date palm cv. Sukary that transferred from conservation medium to normal growth condition were obtained from interaction of conservation medium for 4, 8 and 12 months and Sucrose at $90 \mathrm{~g} / \mathrm{L}$. However Silva et al., (2019) mentioned that Although the plants grown in the culture media supplemented with sorbitol or mannitol produced a low number of senescent leaves, these plants' development was limited, including atrophy in many cases, which are not recommended for in vitro conservation. 


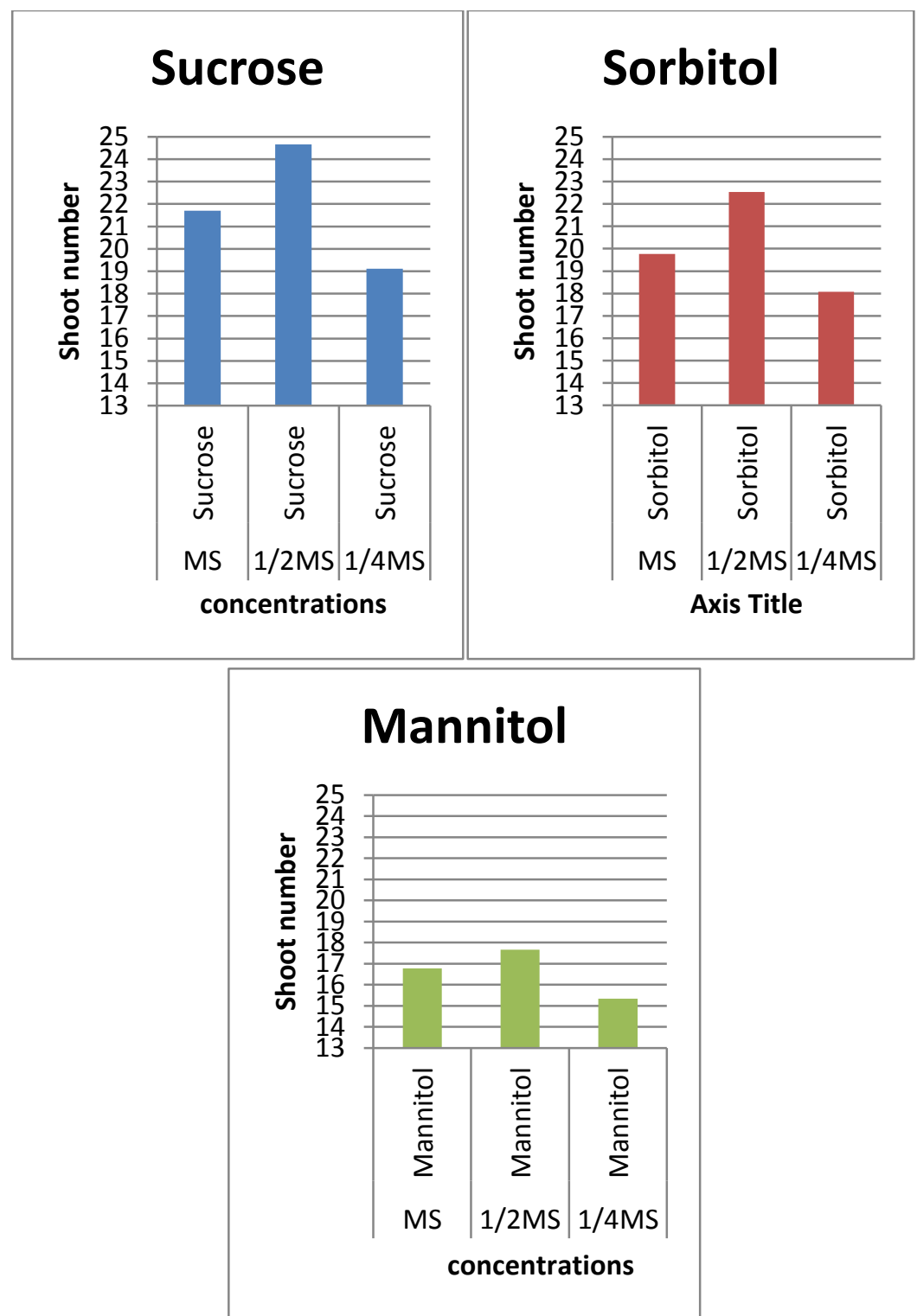

Fig (1). Effect of sugar types and MS media strengths during conversion stage on Shoot number of date palm cv. Amry .

\section{III-5- Shoot length /explant:}

Data presented in Fig 2 cleared that somatic embryo clusters of date palm cv. Amry that conserved on half strength of MS medium supplemented with Sucrose at $0.3 \mathrm{M}$ under slow growth conditions at $15^{\circ} \mathrm{C}$ for 6 month recorded the highest shoot length values when transferred to recovery medium under normal growth condition in comparison to other treatments. These results are in accordance with those obtained by El-Bahr et al., (2016) who recomend using $40 \mathrm{~g} / \mathrm{l}$ mannitol or $20 \mathrm{~g} / \mathrm{l}$ sorbitol for in vitro preservation of Bartamoda cultivar of date palm and $20 \mathrm{~g} / \mathrm{l}$ of sucrose. Regarding the effect of the interaction between MS strengths and Sugar types on shoot length Fig 2, in dictated that there were a significant differences between MS strengths supplemented with different Sugars types where as somatic embryos conserved on half strength MS supplemented with Sucrose at $0.3 \mathrm{M}$ induced maximum level of shoot length as somatic embryos transferred to normal growth medium compared with other treatments. These results are supported by. ElDawayati et al., (2018). They that the lengths of regenerated shoots which proliferated from conserved somatic embryos clusters of date palm Sukarry cv were affected significantly with different sucrose concentrations supplemented to conservation medium during $\left(4,8\right.$ and 12 months) storage period at $15^{\circ} \mathrm{C}$. somatic embryos cluster conserved on conservation medium with addition of sucrose at $90 \mathrm{mg} / \mathrm{L}$ during minimal growth conditions at $15^{\circ} \mathrm{C}$ recorded the highest significant length of regenerated shoots under normal growth conditions for three subcultures after conservations periods, followed significantly by the length of regenerated shoots proliferated from somatic embryos clusters of date palm Sukarry cv preserved on conservation medium supplemented with sucrose at $120 \mathrm{~g} / \mathrm{L}$ 

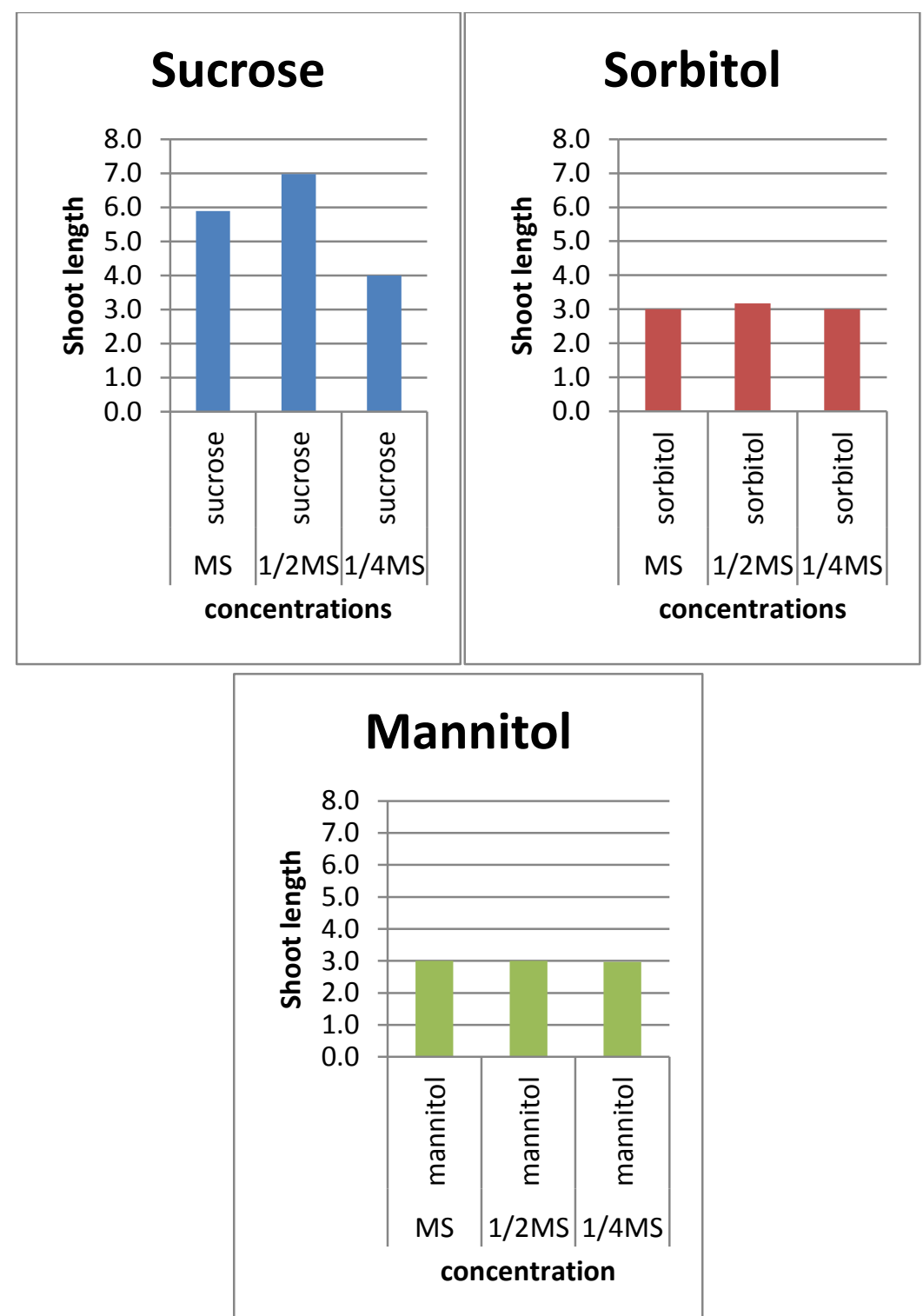

Fig( 2). Effect of sugar types and MS media strengths during conversion stage on Shoot length of date palm cv. Amry •

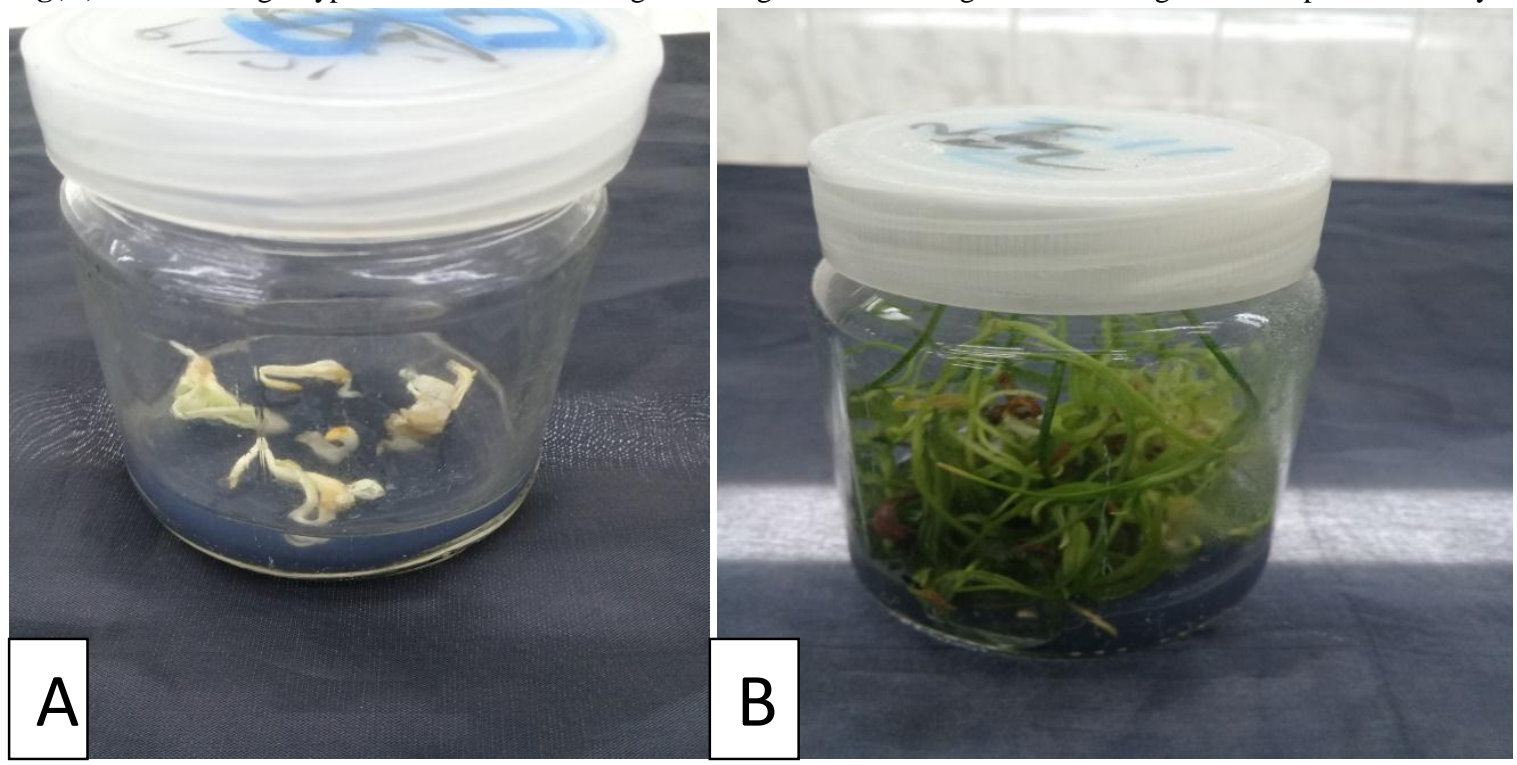

Fig (3): Effect of sugar types and MS strengths of direct somatic embryos conserved temperature at $15{ }^{\circ} \mathrm{C}$ for 6 month of date palm cv. Amry. A) ) before conservation somatic embryo

B) after conservation somatic embryo of explant of Six months after saving 


\section{References}

Al-Khayri, J.M. and Naik, P.M., (2017). Date palm micropropagation: Advances and applications. Ciência e Agrotecnologia, 41(4), pp.347-358.

Baghdadi, S.; Shibli, R.;Syouf, M.; Shatnawai, M.;Arabiat, A. and Makhadmeh, I. (2011). Medium term preservation of wild Crocus (Crocus hyemalis and Crocsmoabiticus) Embryogenic Callus. Jordan J Agri Sci. 7(3), 49548

Bekheet, S.A. (2017). In vitro conservation of date palm tissue cultures. In Date Palm Biotechnology Protocols Volume II (pp. 15-24). Humana Press, New York, NY.

Chauhan, R,; Keshavkant, S.; Jadhav, S. K. and Quraishi, A. (2016). In vitro slow-growth storage of Chlorophytum borivilianum Sant. et Fernand: a critically endangered herb. In Vitro Cell Dev Biol Plant 52:315-321

Chauhan, R., Singh, V. and Quraishi, A. (2019). In vitro conservation through slow-growth storage. in synthetic seeds (pp. 397-416). Springer, Cham.

El-Bahr, M. K.; El-Hamid, A. A.; Matter, M. A.; Shaltout, A.; Bekheet, S. A. and El-Ashry, A. A. (2016). In vitro conservation of embryogenic cultures of date palm using osmotic mediated growth agents. Journal of Genetic Engineering and Biotechnology, 14(2), 363

El-Dawayati, M. M.(2008). Using tissue culture technology to storage some plant tissue of date palm . Ph. D. Thesis, Department of Pomology, Fac. Agric., Cairo Univ., Egypt.

El-Dawayati, M.M.; Baker, E.I.; Gomaa, A.H. and Zayed, Z. (2013). In vitro conservation of date palm shoot tip explants under minimal growth condition. Egypt J Agric Res 91: 1043-1062.

El-Dawayati, M.M. (2017). In vitro conservation of date palm shoot-tip explants and callus cultures under minimal growth conditions. In Date Palm Biotechnology Protocols Volume II (pp. 49-59). Humana Press, New York, USA.

El-Dawayati, M., Baki, M. A. A., and Abdelgalil, L. M. (2018). Effect of different conservation period with different sucrose concentrations on conserving somatic embryo clusters of date palm (Phoenix dactylifera L.) under minimal growth conditions.

Engelmann, F. (2011). Use of biotechnologies for the conservation of plant biodiversity. In Vitro Cell Dev Biol Plant 47: 5-16.

FAO, (2018). The State of World Fisheries and Aquaculture 2018-Meeting the sustainable development goals.

Gantait, S., El-Dawayati, M.M., Panigrahi, J., Labrooy, C. and Verma, S.K.. (2018). The retrospect and prospect of the applications of biotechnology in Phoenix dactylifera L. Applied microbiology and biotechnology, 102: 8229-8259.

Georg,e E.F.;Hall, M.A.and Klerk, G.J. (2008). The components of plant tissue culture media macro and micro-nutrients. Plant Propagation by Tissue Culture. 11365

Hassan, M.M., Taha, R.A. and Ibrahim, I.A., (2016). In vitro conservation of date palm embryos under slow-growth conditions with osmotic agent and abscisic acid. Int J Pharm Tech Res, 9(10), pp.173183.

Lopez-Puc, G. (2013). An effective in vitro slow growth protocol for conservation of the orchid Epidendrum chlorocorymbos Schltr. Tropical and Subtropical Agroecosystems, 16(1), pp.61-68.

Moges A, Karam N, Shibli R. (2003). Slow growth in vitro preservation of African violet (Saintpaulia ionantha Wendl.). Adv. Hort. Sc. 17(4): 223-230..

Muñoz1 M., Díaz D. , Reinún W., Winkler A. , and Quevedo R. (2019). Slow growth in vitro culture for conservation of Chilotanum potato germplasm Chilean Journal of Agricultural Research 79(1) 2635.

Murashige T, Skoog F.A. (1962) .Arevised medium for rapid growth and bioassays with tobacco tissue cultures. Physiol Plant 15:473-479

Negri, V.; Tosti, N. and Standardi, A. (2000). Slowgrowth storage of single node shoots of apple genotypes. Plant Cell Tiss Org Cult 62: 159-162.

Pan, X.J., Zhang, W.E. and Li, X., 2014. In vitro conservation of native Chinese wild grape (Vitis heyneana Roem. \& Schult) by slow growth culture. Vitis, 53(4), pp.207-214.

Rahayu, E. S., Habibah, N. A., and Herlina, L. (2015). Development of in vitro conservation medium of Carica pubescens Lenne \& K. Koch through nutrients concentration reduction and osmoregulator addition. Biosaintifika: Journal of Biology \& Biology Education, 7(1), 22-28.

Sabah, A. H.;Abido, A. I. A;ly, M. Aand Rayan G A (2013). In vitro Preservation of Grapevine (Vitis vinifera L.) Muscat of Alexandria and Black Monukka Cultivars as Genetic Resource. African J Basi \& Appli Sci 5 (2): 55-63.

Shibli, R.; Subaih, W.and Abdelrahman N. (2005). Effect of different carbohydrates on in vitro maintenance of date palm embryogenic callus. Adv. Hort. Sc. 19(1): 172-175.

Schroeder, T. E. (1970). The contractile ring. Zeitschrift für Zellforschung und Mikroskopische Anatomie, 109(4), 431-449.

Silva, T.; dos Santos, C.; Ferreira, Nepomuceno.;Taliane, L.; Soares, J.; Raniere, Ferreira. and Santana, d. (2019). In vitro conservation of Poincianella pyramidalis (Tul.) L.P. Queiroz under minimal growth conditions. Ciência e Agrotecnologia, 43:e014519.

Staikidou, L.; Watson, S.; Harvey, R. and Selby, C. (2005). Narcissus bulblet formation in vitro: effects of carbohydrate type and osmolarity of the culture medium. Plant Cell Tiss. Org. Cult. 80:313-320.

Thakur S, Tiwari, K.L, Jadhav, S.K. (2015). In vitro approaches for conservation of Asparagus racemosus Willd. In Vitro Cell.Dev.Biol. Plant. 51:619-625. 